\title{
Assessing Risk Management in Small Rural Municipalities in Canada
}

\author{
Tom Cooper \\ Memorial University of Newfoundland \\ Pauline Downer \\ Memorial University of Newfoundland
}

\author{
Alex Faseruk \\ Memorial University of Newfoundland
}

This paper explores both the critical success factors and barriers encountered when applying strategic risk management to predominantly smaller municipalities in the Canadian province of Newfoundland and Labrador. These municipalities find themselves in uncertain times due to the impact of demographic shifts, uncertain financial arrangements, technology, and an ever increasingly pace of change. Using content analysis and semi-structured interviews from 133 municipal plans, this study collated information on public sector risk management while addressing the prevailing practice of risk management within these municipalities.

Keywords: Strategic Risk Management, Public Sector Enterprise, Unicipalities

\section{INTRODUCTION}

The application of risk management techniques and approaches have been increasingly recognized as a key element of an effective management and governance framework in various categories of critical organizations. This trend is further manifested through the release of ISO 31000:2009 on Risk Management, which is intended for use by any public, private or community enterprise, associated group or individual. Therefore, it is not specific to any group or sector. What has been underexplored is the area of municipal risk management. A municipality, in this case, is defined as a town or district that has local government. In Canada, municipal governments are local authorities created by the provinces and territories to provide services that are best managed under local control.

Revenue for the municipalities comes predominantly from property taxes and provincial grants and provide services that impact daily lives in numerous ways: from garbage pick-up and public transit to fire services, policing and programs at community centers, libraries and swimming pools. Municipal governments include cities, towns, villages and rural (county) or metropolitan municipalities (Plunkett, 
2017). The term municipality in this case is used to contrast with other local government organizations that are seen in the United States and operate under a different legal and governance framework.

The contemporary understanding of public sector risk management has involved a broadening of the traditional bureaucratic approach to risk beyond the boundaries of purely financial risks. Evidence suggests that, in reality, public sector risk management does not always match the rhetoric (Cooper, 2012). What has been underexplored has been the role of risk management at a municipal level; especially small municipalities that are the norm across North America.

Municipalities deliver a range of services, all of which carry varying degrees of risk. Identifying risks and being prepared to manage them will minimize negative impacts they may have. Risk management is recognized as an acceptable way to carry out operations and demonstrate effective governance. Risks can be managed informally or in a more formal and structured approach. Either way, it is desirable to embed risk management thinking and practice into planning processes so it becomes part of the way operations are conducted and managed within municipalities.

This paper explores critical success factors and barriers to strategic risk management within predominantly smaller municipalities in the Canadian province of Newfoundland and Labrador. Choosing Newfoundland and Labrador is partially through convenience and also because it contains a larger number of very small communities in a large geographic area. Municipalities in the province of Newfoundland and Labrador also increasingly find themselves in uncertain times due to the impact of demographic shifts (most notably by either outmigration from the province or relocation to larger urban areas), uncertain financial arrangements, technology, and an ever-growing pace of change. These drivers represent enormous opportunities and hazards for municipalities. The consequences of the failure to adapt are also significant. For example, changed approaches to business continuity and crises management have also created a whole new dimension to municipal operations that must be considered and formally addressed. All these factors have an impact on the risk profile for that municipality.

Using content analysis and semi-structured interviews, an enhanced mixed methodology approach was employed to explore the question of barriers and key success factors of risk management within municipal governments and the public sector. Specifically, this research collated information on public sector risk management, while addressing the practice of public sector strategic risk management through a series of semi-structured interviews and content analysis of 133 municipal plans. Finally, the potential barriers and key success factors are explored to address strategic risk management for these smaller municipalities in the province of Newfoundland and Labrador.

\section{BACKGROUND}

Most organizations, both private and public, have viewed the process of risk management primarily as an issue of compliance with statutory or regulatory requirements. As a result, risk management within organizations has traditionally occurred within specific areas, such as technology, engineering, regulatory, financial, environmental etc., with little or no coordination. Major risk events such as September 11, natural disasters and governance failures have made it increasingly apparent that the processes, policies and procedures of managing organizational risk must be a cohesive, constant analysis of both the internal and external organizational environment.

Risk is an inherent part of the life of any organization. The operation of any organization involves risk. Organizations, such as municipalities, can be threatened by not managing/mitigating risks, or conversely be rendered powerless by not taking risks. Risk, therefore, involves costs and opportunities; to strike the right balance, municipalities must effectively manage risk.

Organizations of all types and sizes face internal and external factors and influences that make it uncertain whether and when they will achieve their objectives. The effect this uncertainty has on an organization's objectives is by the most basic definition, risk. Due to this uncertainty, the various activities of a municipality involve varying degrees of risk. Organizations manage risk by identifying, analyzing, and then evaluating whether the risk should be modified or avoided. Throughout this process, 
municipalities must communicate and consult with stakeholders, as well as continually monitoring and reviewing the risks being managed.

While all organizations manage risk to some degree, there are principles that need to be satisfied to ensure that the risk management being undertaken is effective. Moreover, an effective approach integrates the process for managing risk into the municipality's overall governance, strategy and planning, management, reporting processes, policies, values and culture. It becomes a core element of a municipality's strategy and operations.

Risk management can be, therefore, applied to an entire municipality, to its many areas and levels, at any time, as well as to specific functions, projects and activities. For example, it can be applied from everything as to addressing the risk around water and sewer upgrades to how to manage employee travel. This wide spectrum of activity creates a significant diversity of risks that require management.

Risk, within a public sector organization, is usually much broader than the traditional private sector financial, operational or capital project risks. Government departments at a regional and community level are responsible for a wide range of services such as the provision of health care, education, protecting the environment, regulating industry and the provision of social security. Service delivery and development all pose some degree of risk. Moreover, regional and municipal governments usually have to deal with a more finite amount of resources than the private sector in addressing these risks (Hood and Kelly, 1999).

Having identified what risk management is, it is important to define why it is important in the public sector. A definition by Hill focused on the public sector describes, "The concept of risk has captured a growing importance in modern society reflects a desire to improve decision making under uncertainty: to maximize the benefits and to minimize the costs." (Hill, n.d., p.3). Using Hill's definition, the importance of risk management to municipalities would seem to be clear.

Risks that can be precisely quantified receive most of the attention from risk managers while socalled soft risks, however significant, often receive little notice (Hansson, 2010). The perplexing element for public sector risk managers is that the majority of the risks they face are essentially soft risks and ultimately more difficult to manage through traditional avenues, such as risk transfer. Municipalities need to strategically plan to manage their risks around infrastructure as well as other risks such as operations and community planning. The management of these soft risks should consequently be of concern to communities, regions and the overall public sector.

Definitions of strategic risk are numerous including: Slywotzky and Drzik (2005, p.80) as "an array of external events and trends that can devastate (an organization's) growth trajectory and shareholder value"; Chapman (2006, p. 225) as: "the risk associated with initial strategy selection, execution, or modification over time that results in a lack of achievement of overall objectives"; Johnson et al. (2006, p. 369) as "strategic risk can be seen as the probability and consequences of a failure of strategy."

The interesting element of the definition by Johnson et al. (2006) is that it focuses on the strategic rather than solely the element of risk. The probability and consequences of a failed strategy around an issue, such as the management of municipal infrastructure may also have more relevance to communities and regions as they consider how to manage strategic risk to be part of their governance and operations. The identification and management of the strategic risks around municipal infrastructure then becomes an essential element in any planning process.

\section{APPROACHES WITHIN THE STUDY}

In this study, three sources and approaches are used to gather data and to analyze them. Using three sources and approaches also helped to more completely understand importance of risk management for smaller municipalities in the province of Newfoundland and Labrador.

In the first approach, critical success factors and barriers to strategic risk management for municipalities within the province of Newfoundland and Labrador are explored. Using content analysis and semi-structured interviews, an enhanced mixed methodology approach is used to explore the question of barriers and key success factors of strategic risk management within municipal governments and the public sector. This study collated information on public sector risk management and addressed the 
practice of public sector strategic risk management through a series of content analysis of 133 municipal plans.

In the second approach, municipal infrastructure risk in the province of Newfoundland and Labrador is examined. The information was provided in aggregate by the provincial government and focused on capital assets as well as other infrastructure that a municipality might have. Although predominantly limited to operational and financial risk, this information provided a useful proxy to some of the more significant strategic risks. As a result, in an analysis of 269 communities, it was possible to see in aggregate, significant amounts invested in municipal infrastructure in Newfoundland and Labrador.

Finally, in the third approach the operational risk literature is reviewed to provide a better understanding of the aggregate operational risks facing municipalities in managing their operations, which identified good practices and existing models for identifying the full spectrum of operational risks facing municipalities. Lastly, it outlined a good practice model for managing the operational risks around municipal infrastructure. This model was presented to over 200 municipal leaders to seek feedback and clarification in workshops and conferences over a three-year period.

Overall, this study provides risk management concepts, models and processes, which can then be applied at any type of municipality, no matter how large or small. Moreover, it aspires to assist mayors, councillors, town managers and staff in understanding the principles required to effectively manage risk in their area of responsibility. It is not meant to provide specific, prescriptive checklists and procedures but rather provides information on what a municipality should do to embed risk management. It is research on the how, rather than the what, of effective risk management for municipalities.

\section{RESEARCH FINDINGS}

This study found that most of the critical infrastructure in the province of Newfoundland and Labrador is interlinked. For example, the risks around the continuity of supply of critical infrastructure often depends on the availability of other critical infrastructure services.

Newfoundland and Labrador is the ninth-most populous province in Canada with 519,716 residents as of 2016 and is the seventh-largest in land area at $370,514 \mathrm{~km}^{2}(143,056 \mathrm{sq} \mathrm{mi})$ (statistics Canada). Newfoundland and Labrador has 271 municipalities including 3 cities and 268 towns, which cover only $2.2 \%$ of the territory's land mass, but are home to $89.6 \%$ of its population.

Towns are created by the Government of Newfoundland and Labrador in accordance with the Municipalities Act, 1999, whereas the three cities were incorporated under the City of Corner Brook Act, the City of Mount Pearl Act and the City of St. John's Act. These acts grant the power to enact local bylaws and the responsibility to provide local government services. St. John's is Newfoundland and Labrador's capital and largest municipality by population with 108,860 residents and land area with $445.88 \mathrm{~km}^{2}$ (172.16 sq mi). Tilt Cove is its smallest municipality by population with five residents, and Brent's Cove is the smallest municipality by land area with $1.02 \mathrm{~km}^{2}(0.39 \mathrm{sq} \mathrm{mi})$.

In aggregate, it was possible to see that the degree and complexity of risks at a municipal level is increasing as organizations becomes more reliant on shared information systems and convergent communication technologies, such as the internet. There are a range of threats or hazard risks that can damage or destroy critical infrastructure and disrupt the continuity of essential services, including natural disasters, pandemics, accidents, negligence, criminal activity, and terrorist attack.

Newfoundland and Labrador's municipal risk was difficult, at times, to separate from other government entities, namely provincial and federal government levels. This responsibility of risk is effectively shared between owners and operators of critical infrastructure, municipalities, the provincial government as well as the Canadian government. As part of the content analysis and the research gathered at a community level, some of the more pertinent risks identified include:

- Financial-major risks for municipalities in being able to fund their municipal infrastructure given current value and amortization rates.

- Operational-declining levels of infrastructure may affect the ability of municipalities to meet operational goals and services. 
- Economic-current as well as future economic conditions may affect the ability of municipalities to generate or access the necessary sources of revenue to pay for upgrading or replacement of infrastructure. A concentration of municipal infrastructure in the St. John's Census Metropolitan Areas (CMA) may also impact the ability of some municipalities beyond the Avalon Peninsula to engage effectively in sustained economic development.

- Environmental-declining or obsolete infrastructure, especially in asset classes such as roads, streets and bridges, as well as water and sewer, may lead to significant environmental risks for municipalities and the province as a whole.

- Social-expectations around the ability of municipalities to service community member expectations around infrastructure (fixing roads, providing adequate land around recreation) may be impacted by declining or obsolete infrastructure.

- Legal/Political-the ability of municipalities to comply with current and new provincial, as well as federal regulations that are affected by their infrastructure may be compromised by inadequate or obsolete assets.

Major risk events, such as 911, and natural disasters, such as hurricanes, have cultivated a new and innovative way of thinking about risk within municipalities across North America and beyond. Thinking about risk management is encouraged to be more than loss mitigation or reduction. It is now a proactive and structured method for identifying, measuring and harnessing opportunity. For example, when implemented and maintained, the management of risk enables a municipality to achieve a number of strategic and operational objectives including:

- increase the likelihood of achieving objectives;

- encourage proactive management;

- be aware of the need to identify and treat risk throughout the municipality;

- improve the identification of opportunities and threats;

- comply with relevant legal and regulatory requirements and municipal management norms;

- improve mandatory and voluntary reporting;

- improve governance;

- improve stakeholder confidence and trust;

- establish a reliable basis for decision making and planning;

- improve controls;

- effectively allocate and use resources for risk treatment;

- improve operational effectiveness and efficiency;

- enhance health and safety performance, as well as environmental protection;

- improve loss prevention and incident management;

- minimize losses;

- improve organizational learning; and

- improve organizational resilience.

Although the concepts of risk management are maturing to include maximization of opportunity, as well as loss minimization, another dimension of risk for municipalities has emerged in recent years: uncertainty. The notion of managing uncertainty is becoming more a reality than a far-fetched thought especially for municipalities. The attitude 'it won't happen to us' has rapidly evolved in the last five years to 'that could so easily have been us.' In risk management, it is often thought what is not measured is not managed. When considering uncertainty and the impact the unknown may have on a municipality, measuring uncertainly is translated into the identification of the worst-case scenario.

Uncertainty by its very nature is difficult to predict and quantify. Proactive thinking and a planned response have at least the same importance in planning for uncertainty as they do in cases of more tangible risks. As was witnessed in Newfoundland and Labrador municipalities, as well as elsewhere, disaster or unexpected outcomes can occur at any time. In the case of uncertainty-based risk, the direct cause is generally unpredictable and beyond reasonable control, so how can one manage it? In these 
circumstances, the focus can be directed toward planning to minimize operational disruptions and ensuring that plans are in place to respond to the crisis, as well as opportunities if they occur. However, the plans that were available were not comprehensive in their identification or assessment of risks. Moreover, especially for smaller municipalities, this study found the majority of organizations had no formal plan to address uncertainty based risk.

Given the breadth and multiplicity of the various functions undertaken in municipal management, an appropriate range of risks needs to be adequately identified and managed. Consistent with ISO 31000 , risk management requires a framework of process and support to allow risk information to move quickly and efficiently around the functions in the municipalities.

In consultation with municipalities, it was found that risk implies different connotations to different people depending on their background, their experience, and their understanding of risk. The same would seem to hold true at a municipal level. Risk management evolved predominantly from the engineering, safety, finance and insurance disciplines. Each background advocates a slightly different school of thought on risk. Some support the concept of zero tolerance; others adopt the approach of 'reduction of risk as far as is reasonably practical.' It is, therefore, important for a municipality to keep this in mind when disseminating risk information, to ensure that the appropriate message is being communicated.

In aggregate, Figure 1 three types of risk found in a municipality:

FIGURE 1

THREE TYPES OF RISKS FOR MUNICIPALITIES

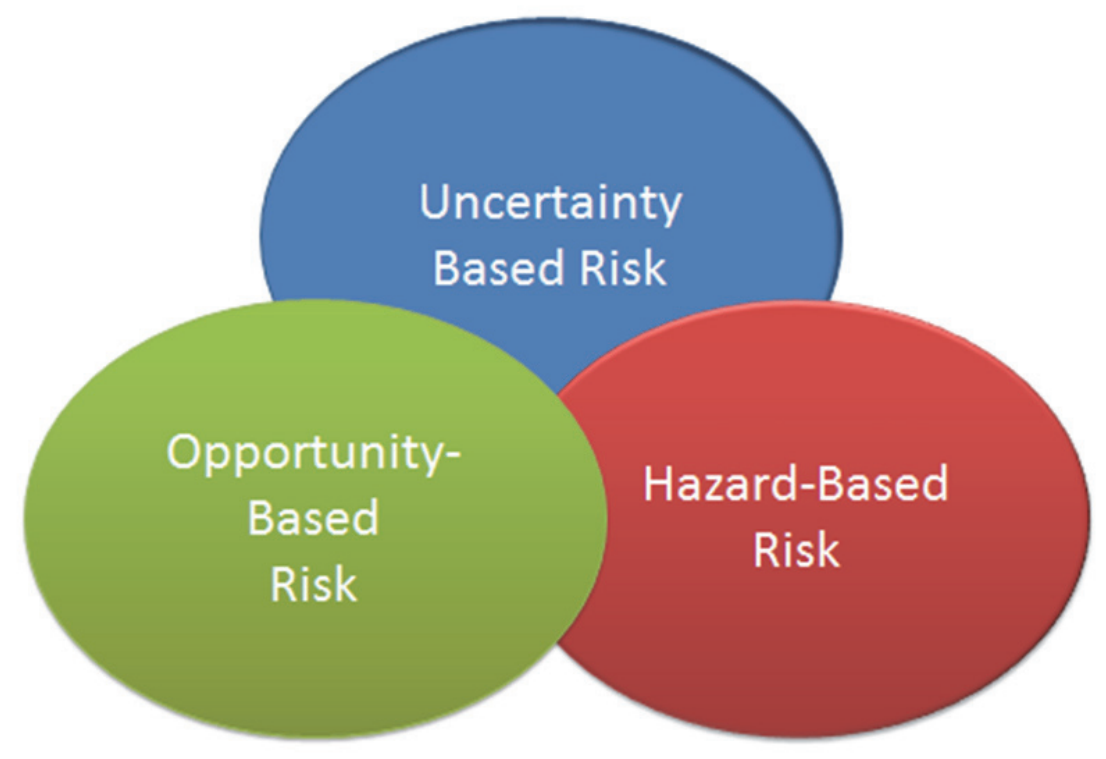

For municipalities, each type of risk has distinct characteristics that requires a different management approach or analysis technique. An understanding of the three types of risk enables municipal leaders, managers, and staff to select the most appropriate and effective management approach for the type of risk.

\section{UNDERSTANDING OPPORTUNITY-BASED RISK}

Opportunity risk is the potential gain or the positive impact to objectives for municipalities. Opportunity-based risk can be tangible and or intangible, is often quantified in dollar terms and can have a positive or negative outcome on a municipality. Examples of opportunity-based risk for municipalities are:

- expanding tax base and/or property acquisition; 
- economic development activities; and

- developing infrastructure to assist in attracting people into the community.

\section{UNDERSTANDING UNCERTAINTY-BASED RISK}

Uncertainty-based risk is the risk associated with unknown and unexpected events. These events may be catastrophic in nature and include accidents or acts of God/force majeure. Uncertainty-based risks are unknown or extremely difficult to quantify, are catastrophic or disastrous in nature, can be very costly, are associated with a negative outcome and are outside the municipality's sphere of control or influence. Examples of uncertainty-based risk are:

- water and sewer damage by flash flooding or hurricanes;

- declining tax base; and

- acts of vandalism to critical municipal infrastructure.

\section{UNDERSTANDING HAZARD-BASED RISK}

Hazard-based risk is the risk associated with a source of potential harm or a situation with the potential to cause harm. Hazards are generally grouped into the following categories:

- physical hazards-these include noise, heat, cold, vibration and pressure;

- chemical hazards-some of the consequences of chemical hazards are explosions, flammability, corrosion, poisoning, toxicity and carcinogenicity;

- biological hazards these include viruses, bacteria, fungi (including mold) and other organisms;

- $\quad$ ergonomic hazards associated with poor workspace design, layout or activity and equipment usage; and

- psychological hazards-sources of psychological stress that can result in physical or psychological harm.

For municipalities, all these hazards may impact their operations and specifically their municipal infrastructure risk. Many municipalities in the study were quite good at recognizing hazard-based risks. Predominantly this was because of provincial or federal regulations requiring compliance. As a result, hazard-based risks are usually known, are readily quantifiable, are tangible, and impact predominantly on safety. Examples of hazard-based risks are:

- management and usage of hazardous chemicals, such as chlorine in municipal pools;

- confined space entries, such as municipal sewers;

- contamination to a municipal water supply; and

- ergonomic issues with the implementation of new equipment for office-based employees.

Overall, municipalities, especially smaller ones, were quite good at recognizing and managing hazard-based risks. On the other hand, opportunity and uncertainty-based risks were relatively not as well identified, assessed, or managed. In order to assist organizations in the how to manage risk, propose a number of models in applying risk management as part of the municipal operations life cycle.

\section{APPLICATIONS, RISK MANAGEMENT AND THE MUNICIPAL OPERATIONS LIFE CYCLE}

Municipal management is about planning and managing its operations life cycle. A municipality's operations life cycle can be described as four distinct, but linked stages: strategy and planning, infrastructure creation or acquisition, operation or service delivery and disposal. Figure 2 illustrates the stages of a municipality's operations life cycle. 
FIGURE 2

MUNICIPAL OPERATIONS LIFE CYCLE

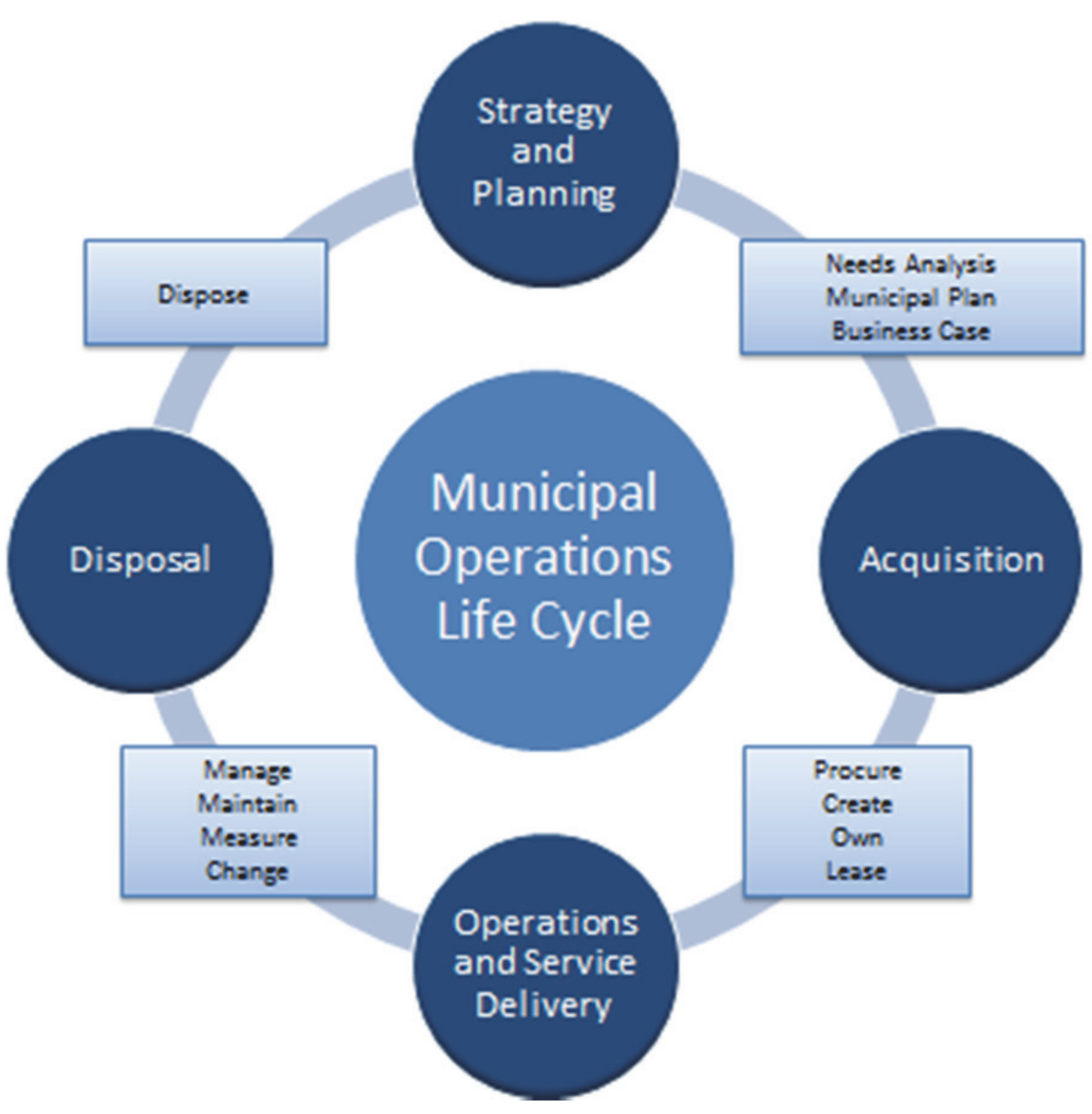

\section{Phase 1 - Strategy and Planning}

Every municipality, regardless of age and size, requires a level of planning and foresight to ensure that it meets the requirements of its taxpayers and wider society. Strategy and planning includes needs assessment, development of capability requirements, criteria for acquisition or creation of infrastructure, and the establishment of boundaries (financial, geographical, time-based), as well as a strategic approach to operations. The objectives of risk management in this phase of the operational life cycle include:

- identifying major contributors to risk and the significant factors involved;

- providing input into the municipal planning process and assessing the overall adequacy of the municipal plan;

- identifying and evaluating possible safety measures in the plan;

- providing information to assist in developing procedures for normal and emergency conditions;

- evaluating risk with respect to regulatory and other requirements;

- evaluating alternative planning concepts; and

- providing a risk-based approach to the development of municipal strategies and plans. 


\section{Phase 2 - Acquisition}

Acquisition includes the development of new infrastructure, as well as the purchase of new materials and supplies such as snow removal trucks. It also includes the acquisition of outsource service such as garbage collection or IT technical support. Acquisition, in its broadest context, should include the risks around everything from hiring a new employee to deciding to build a new town hall.

The objectives of risk management in this phase of the life cycle include:

- complying with legislative and regulatory requirements;

- providing a risk-based approach to purchasing, hiring, contracting and outsourcing; and

- incorporating a risk-based approach in cost-benefit analysis and decision-making in procurement.

\section{Phase 3 - Operations and Service Delivery}

Municipal operations and service delivery is typically the stage of the longest duration in the municipal operations life cycle. The requirements for operating a municipality are largely determined by size. Larger municipalities will deliver different services and conduct more diverse operations than a smaller one.

Effective management of a municipality's operational life cycle will impact on the productivity of the municipality, the health, security and safety of the community, as well as visitors. It will also partly determine the environmental impacts of a municipality's operations.

The objectives of risk management in this phase of the life cycle include:

- providing input into the optimization of normal operating, maintenance and emergency procedures;

- providing information on the significance of the risk for operational decision-making;

- evaluating the effects of changes in organizational structure, operational practices and procedures and system components;

- complying with legislative and regulatory requirements; and

- monitoring and evaluating experience for the purpose of comparing actual performance with municipal goals, objectives, policies and procedures.

\section{Phase 4 - Disposal}

Infrastructure disposal is the final stage of a municipality's operational life cycle. Disposal may involve sale or demolition and/or replacement of various parts of the infrastructure. It can also including deciding to terminate the contract of an employee, not deciding to offer a service anymore to the community or ultimately tearing down a building no longer being used.

The objectives of risk management in this phase of the life cycle include:

- evaluating risks related to disposal activities and ensuring that relevant requirements can be met; and

- providing input into disposal procedures.

The scope and context of the application of risk management across municipalities may range from public safety in local council meetings to a risk assessment within a major water and sewer upgrade. Risk management is a process that can be applied in any context and to any task or activity. Differences in application will be in the tools, techniques, and risk approach used.

\section{THE RISK MANAGEMENT PROCESS}

Risk management is an integral component of the municipal life cycle. The entire risk management process is iterative, enabling it to be repeated many times with additional or modified risk evaluation criteria, thereby leading to continuous improvement. 


\section{FIGURE 2 \\ RISK MODEL FOR MUNICIPALITIES}

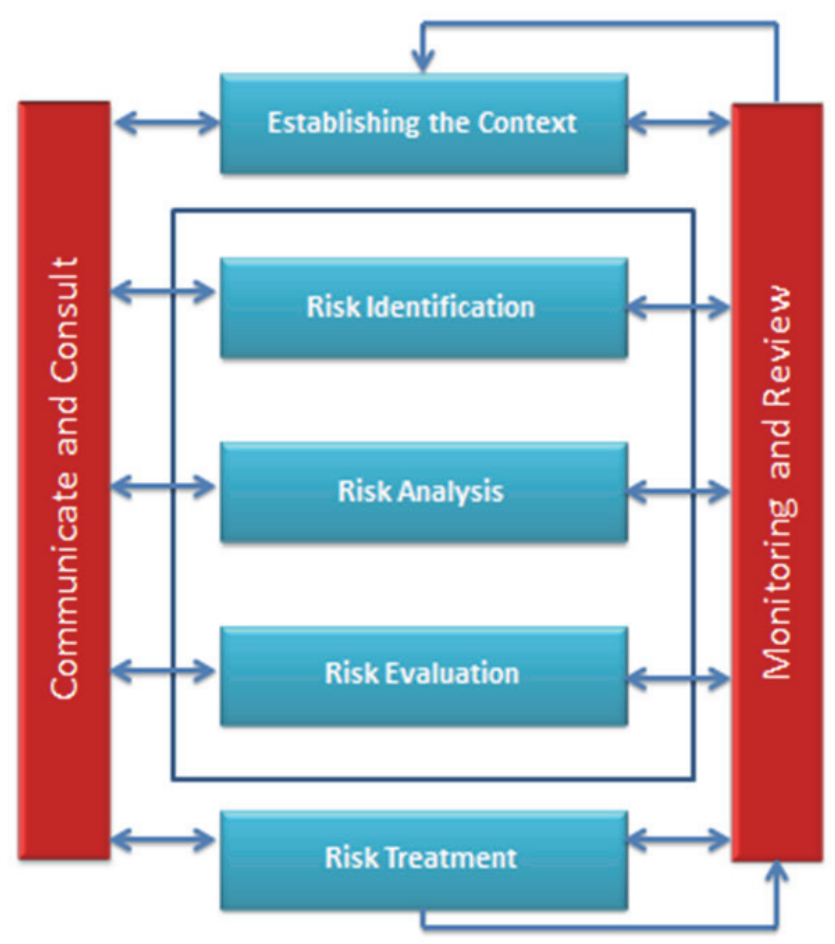

Based on ISO 31000, the elements of the risk management process for municipalities are summarised in Figure 2, and are as follows:

- communicate with the internal and external stakeholders as appropriate at each step of the risk management process.

- determine the internal, external risk management context, and establish the structure of the analysis and the criteria against which risk will be assessed.

- identify, as the basis for further analysis, what can happen, why and how events could delay, prevent or enhance the achievement of organizational objectives.

- analyze the range of possible consequence and how they might occur. Determine the likelihood of each consequence and hence the level of risk. The risk will depend on the effectiveness of existing controls.

- compare the estimated levels of risk with pre-established risk-criteria and decide whether to treat a risk based on the potential benefits or adverse outcomes. Risks can then be ranked to identify priorities for their management.

- risks identified as low priority and are tolerable, may not require treatment. For other risks, develop and implement a management plan, which should include consideration of funding and other resources, and timeframes.

- monitor and review the risks, the performance of the risk management system, and the changes that may affect it.

\section{Communicate and Consult}

Communication and consultation are significant considerations throughout the risk management process especially for municipalities. Communication and consultation may be internal to the 
municipality, or external, between the municipality and its stakeholders, such as the provincial or federal government.

To ensure effective communication, municipalities should develop and implement a communication strategy or plan as early as possible in the risk management process. This strategy or plan should identify internal and external stakeholders and communicate their role and responsibilities in the process, as well as address issues relating to risk and management.

Consultation is a broad two-way process. It typically involves discussing or seeking input to a range of stakeholder groups and exchanging information and views. It can include a variety of techniques, ranging from informal community meetings with key individuals to formal meetings. It can involve input into the decision-making process from a range of external sources, and access to information that would not be available otherwise. When setting up a consultation process, the extent to which external input should influence the municipality's final decision must be carefully defined.

Stakeholder perception of risks can vary due to differences in assumptions, values, culture, personal beliefs or concerns as they relate to the risk or issue under discussion. Stakeholders are likely, therefore, to make judgements of the acceptability of a risk on this basis. For example, a private sector company that is situated in a municipality is going to have a different perception of risk than the provincial government. Stakeholders can have a significant role in the decision-making process, so their perceptions of risks, as well as their perceptions of benefits, should be identified, understood, addressed and recorded.

Stakeholder communication should incorporate regular progress reports on the development and implementation of the risk management plan and, in particular, provide relevant information on the proposed treatment strategies, their benefits and planned effectiveness. The communication of this type of information to stakeholders is one of the indicators of effective corporate governance.

\section{Establish the Context}

The risk management process occurs within the framework of a municipality's strategic, internal, and external and risk management context. Establishing the context defines the basic parameters within which risks must be managed, and sets the scope for the rest of the risk management process.

Before any risk management activity is commenced at any level of a municipality, it is important to review and understand the municipality's structure, goals, objectives and functions. This is when the municipality examines the risk management activity in question against its own internal context, so that subsequent risk decisions are not made in isolation from its broader goals and objectives. This approach encourages long-term and strategic thinking. For municipalities, managing risk is often about avoiding a long-term adverse consequence and planning for long-term opportunities.

Establishing the external context defines the environment in which a municipality operates. This involves an examination of how the municipality and its operations impact, and is impacted by, external factors and influences, including social, economic, legal, cultural, environmental, financial, operational, business, competitive, political, public and taxpayer perceptions of image and reputation. Analysis of these factors identifies the municipality's strengths, weaknesses, opportunities and threats.

When considering the external context, it is also important to include both internal and external stakeholders. Their objectives and perceptions of risk should be considered as well as a means to communicate and consult with these stakeholders. Establishing the risk management context defines the context of the activity or issue under examination and includes objectives, scope, boundaries and the municipal department(s) involved. The process should be undertaken with the full consideration of the need to balance cost, benefits and opportunities.

\section{Develop Risk Criteria}

Risk criteria are those against which risk is evaluated to determine if treatment is required. They are created by a municipality as part of establishing the context, but can be further refined as risks are identified and analyzed. Risk criteria are also referred to as the acceptable level of risk for a specific activity or event. In determining the criteria, the dimensions of risk need to be measured. These criteria 
must be appropriate to the type of risk and the risk dimension for the municipality. Establishing the risk criteria also involves the determination of the following:

- timeframe;

- resources required;

- roles and responsibilities;

- additional expertise required;

- internal and external relationships, e.g. projects, municipal departments;

- life cycle considerations;

- record-keeping requirements; and

- depth of analysis required.

The depth of analysis required is dependent on the type of risk, the information that needs to be communicated and the best method for communicating this information. This critical stage will be determined by a combination of the following:

- complexity of the activity;

- potential consequence and severity of potential outcome;

- importance of the activity to the achievement of the objectives;

- information that needs to be communicated to stakeholders; and

- types of risks and hazards associated with the activity.

Overall, for a municipality developing the risk criteria involves structuring the activity or issue under examination into a sequential set of steps or elements. These steps or elements of the activity or issue then provide a framework for detailed analysis. The structure chosen will depend upon the type of activity or issue, its complexity, as well as the context of the risk.

\section{Identify the Risks}

A systematic identification process appropriate to the municipality and its operations is essential so that significant risks are not overlooked. Identification should include all risks, whether or not they are under the control of the municipality. All aspects should be considered, including those associated with the service being provided, personnel, equipment, environmental factors, legal requirements and, where appropriate, social/political factors. Problem areas and risks are identified with the help of reliable sources.

Risk identification also involves examining all sources of risk and the perspective of all stakeholders, both internal and external. It is important to identify each source so that the analysis can consider the contribution each makes to the probability and the potential consequences of the risk. The aim of risk identification is to develop a comprehensive list of risks impacting the municipality's objectives.

\section{Analyze the Risks}

Risk analysis involves consideration of the sources of risk, their consequences and the probability that those consequences may occur. Factors that affect consequences and probability need to be identified. Risk is analyzed by combining consequences and probability in the context of existing control measures.

In this review of the smaller municipalities, it was noted that risk analysis can be confusing, because such a wide range of tools are available. The essential elements of risk analysis are:

- identification of existing strategies and controls;

- determination of individual elements (consequence and likelihood);

- application of appropriate analysis methods and tools;

- estimation of the level of risk by combining consequence and probability; and

- consideration of uncertainties in the estimates.

The purpose of risk analysis is to provide information to decision makers within a municipality, whose decisions may concern priorities, treatment options, or balancing costs and benefits. Just as decisions differ, the information needed to make these decisions differs. Not all areas within the operational management of a municipality are able to use the same risk assessment technique. 
Municipalities involved in specialist areas of risk management (such as large urban areas) need to tailor their analysis tool to suit their operating context and consequently, the selected risk criteria.

Risk evaluation involves comparing the level of risk found during the analysis process with previously established risk criteria, and deciding whether these risks require treatment. This step is about deciding whether risks are acceptable or need treatment. Low or tolerable risks may be accepted. Acceptable means nothing needs to be done, except monitoring and periodic review to confirm the risks remain at this level. If risks are not low or tolerable, they must be treated.

One of the reasons risks need to be formally identified and managed by a municipality is to provide assurance that the risks are not only known, but also accepted at the appropriate level and that the appropriate people are aware of them. A risk may be accepted for the following reasons:

- the cost of treatment far exceeds the benefit, so that acceptance is the only option (applies particularly to lower ranked risks);

- the level of the risk is so low that specific treatment is not appropriate with available resources;

- the opportunities presented outweigh the threats to such a degree that the risk is justified; and

- the risk is such that there is no treatment available; for example, the risk that a project might be terminated following a change of government is not within the control of the municipality

Risk in municipalities is managed by tapping into the processes and structures within the organization. In this review of Newfoundland and Labrador municipalities, some of these processes and structures may already be in place but lack a level of formalization that results in consistency and effective operations. However, some of these structures and applications of process are replaced by an organizational culture that encourages individuals to 'do the best thing' for the municipality.

\section{CONCLUSIONS}

The study provided risk management concepts, models and processes which can be applied to any type of municipality no matter how large or small. It aspires to assist mayors, councillors, town managers and staff in understanding the principles required to effectively manage risk in their area of responsibility.

There are two aspects of risk management: the risks themselves, and the framework or program that enables the municipality to manage risk in a structured and ordered manner. Both aspects need to be considered in better addressing risk. Too often risk is managed informally based on the extensive experience and knowledge of municipal employees and leaders. With the demographic changes in the province of Newfoundland and Labrador, this widespread knowledge and experience may dissipate and thereby lessen the ability and impact of managing risk informally. By adopting a structured approach to how risk is managed and communicated, improvements in municipal organization performance can be achieved, and a culture of sensible risk-taking will emerge. Moving beyond the informal to a more structured, formal approach to managing operational risk for the municipality is essential for success.

At the same time, the informal approach to risk cannot be discounted. The development and identification of a positive risk culture within a municipality is not an easy task. So how is it developed? The answer lies in the relationship between a municipal environment and the demonstrated or adopted behaviours of its mayors, councillors and staff. An ideal culture is one where understanding, managing and taking calculated and acceptable risk is part of a municipality's day-to-day operations.

Adopting a framework for managing risk will create an environment that will influence behavior and eventually shape the culture, beliefs and attitudes of those in the municipality (Figure 4). Culture is often described as 'the way things are done around here.' In a negative risk culture, people are risk-adverse, ignorant of risk or overconfident in their risk-taking. In a positive risk culture, accepting risk at the right level is just part of how things are done. It takes time to develop and shape a culture, so municipalities need to be persistent with implementing a consistent, formal approach to risk. 


\section{FIGURE 4 \\ ADOPTING A RISK CULTURE}

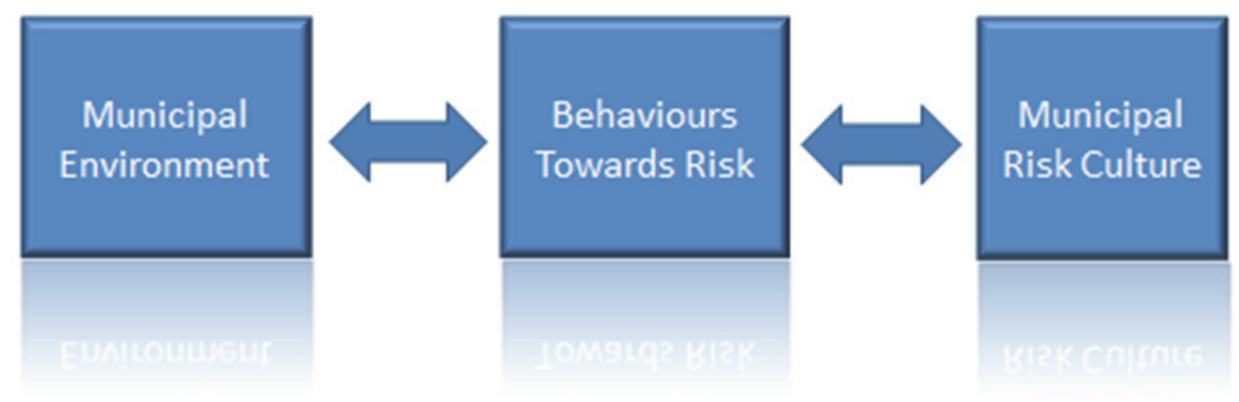

All municipalities are not the same. They differ by size, urban vs. rural, history and services delivered. Diversity creates risk for municipalities. Establishing the internal and external context in identifying, analyzing and addressing risk is also an important element in municipal management. Part of municipal management is also developing an understanding what the community does and does not do. Determining the significance of services and activities, and accompanying risks, in the achievement of the municipality's goals and objectives should be considered in any effective approach to risk management. Specifically the objectives of the service being delivered and the activity being undertaken should be aligned with the overall strategic objectives and plan of the municipality.

Municipalities also need to decide what the output of the risk management process will be. For example, there could be a risk assessment of a specific class of municipal infrastructure. The purpose of the assessment and analysis and why it is being used (training employees, or a council presentation or deciding whether to enter into a contract) should also be part of the risk management process. The output and purpose of the risk management process will determine the most appropriate structure for the assessment and the type of documentation required.

Overall, to embed the risk management process, a municipality must clearly define and communicate the reasons for adopting a model to managing risk. Effective risk management planning and implementation is an essential component of the practice of municipal management and governance. Delivering on strategies that enable the municipality to realize opportunities in their operations, while appropriately managing risk, is essential for long term community sustainability and viability.

To ensure community sustainability and viability, the study found that risk management processes which a municipality can apply should be consistent with ISO3100:2009. Key concepts and processes including communication and consultation, establishing the context, risk identification, analysis and evaluation as well as treatment, monitoring and reviewing of risks are essential for municipalities managing risk.

In this study, using content analysis and semi-structured interviews, an enhanced mixed methodology approach was used to explore the question of barriers and key success factors of risk management within municipal governments in Newfoundland and Labrador. The study found that that risk management has evolved from being more than just a checklist of hazards that organizations needs to avoid and that the process of risk management has become more proactive rather than simply being reactive. Managing risk is as much about capitalizing on opportunities and it should be part of a municipality's strategic and operational planning as well as decision making. It requires a structured framework that will allow the management of risk to become second nature to mayors, councillors and town staff regardless of the size of the municipality. Risk management must be an essential part of the planning and operations of any municipality. 


\section{REFERENCES}

AbouRizk, S., Siu, K.L., \& Allouche, M. (2005). Edmonton bridges the gap. Summit, 10-11.

ACT Health. (2010). Graphic illustration of strategic management frame work. Strategic Asset Management Framework for Major Equipment 2010. Retrieved from http://www.health.act.gov.au/c/health?a=dlpubpoldoc\&document=2264

Asset Management: A Best Practices Guide. (2008). Retrieved from http://www.epa.gov/ogwdw/smallsystems/pdfs/guide_smallsystems_asset management best practices.pdf

Bartley, W. H. (2002). Life cycle management of utility transformer assets. Hartford Steam Boiler Inspection \& Insurance Company.

Boholm, $\AA$. (2010). On the organizational practice of expert-based risk management: A case of railway planning. Risk Management, 12(4), 235-255.

Braig, S., Gebre, B., \& Sellgren, A. (2011). Strengthening risk management in the US public sector.

Buurman, M., Delfgaauw, J., Dur, R., \& Van den Bossche, S. (2012). Public sector employees: Risk averse and altruistic? Journal of Economic Behavior \& Organization, 83(3), 279-291.

CBCL Limited. (2012). Managing Municipal Infrastructure in a Changing Climate. Retrieved from http://www.municipalitiesnl.com/userfiles/files/Climate\%20Change\%20Workbook\%20low\%20re s.pdf

Cespdes, E.V., Shapiro, B.P., \& Ross, E. B. (2011). Pricing, profits and customer value, (Note: 9-811016). Boston, MA: Harvard Business School.

Chapman, R.J. (2006). Simple tools and techniques for enterprise risk management. Chippernham, UK: John Wiley \& Sons, Ltd.

City of Edmonton. (2012). Management Tools. Retrieved from http://www.edmonton.ca/city_government/initiatives_innovation/management -tools.aspx

City of Edmonton. (2012). Risk Assessment. Retrieved from http://www.edmonton.ca/city_government/initiatives_innovation/risk -assessment.aspx

Coe, D. (2005). Risk based bridge asset management. In Australian Small Bridges Conference, 2005. Sydney, New South Wales, Australia.

Cohen, M. A., \& Kunreuther, H. (2007). Operations risk management: overview of Paul Kleindorfer's contributions. Production and Operations Management, 16(5), 525-541.

Cook, M., Mukharji, P., Kiefer, L., \& Pertruzzi, M. (2005). Working your assets to boost your growth. Supply Chain Strategy, 1(1), 4-6.

Cooper, T. (2012). Exploring strategic risk in communities: evidence from a Canadian province. Journal of Enterprising Communities: People and Places in the Global Economy, 6(4), 350-368.

Corvellec, H. (2010). Organizational risk as it derives from what managers value: A practice-based approach to risk assessment. Journal of Contingencies and Crisis Management, 18(3), 145-154.

Davis, G. (2006). Strategic Municipal Asset Manager: The New Profession of "Accountineering". Retrieved from https://www.hamilton.ca/NR/rdonlyres/CCEA5674-E020-48C4-9EDAB354C5BEE14B/0/Accountineering.pdf

Dolan, R. J., \& Courville, J. T. (2009). Principles of pricing. Harvard Business School Pub.

E. I. du Pont de Nemours and Company. (2005). Delivering Operational Excellence to the Global Market-A Dupont Integrated Systems Approach. Retrieved from http://www2.dupont.com/Consulting_Services/pt_BR/assets/downloads/OP\%20E_White\%20Pap -er_FINAL_12\%2014\%2005.pdf

Earle, T. C. (2010). Trust in Risk Management: A Model-Based Review of Empirical Research. Risk Analysis, 30(4), 541-574.

Ehrhardt, D., \& Irwin, T. (2004). Avoiding customer and taxpayer bailouts in private infrastructure projects: Policy toward leverage, risk allocation, and bankruptcy. World Bank Policy Research Working Paper, 3274. 
El-Diraby, T. E. (2007). Water and wastewater asset management in the GTA: Challenges and opportunities. Toronto, ON: Residential and Civil Construction Alliance of Ontario Enterprise Risk Management Framework and Policy. (2010). Sol Plaatje Municipality Risk Management Unit. Retrieved from

http://www.solplaatje.org.za/downloads/policy/SPM\%20Risk\%20Management\%20Framework\% 2011\%2008\%2010.pdf

Ezell, B. C. (2007). Infrastructure Vulnerability Assessment Model (I-VAM). Risk Analysis, 27(3), 571583.

Ezell, B. C., Farr, J. V., \& Wiese, I. (2000). Infrastructure risk analysis of municipal water distribution system. Journal of Infrastructure Systems, 6(3), 118-122.

Ezell, B. C., Farr, J. V., \& Wiese, I. (2000). Infrastructure risk analysis model. Journal of Infrastructure Systems, 6(3), 114-117.

Faith-Ell, C., \& Arts, J. (2009, May). Public Private Partnerships and EIA: Why PPP are Relevant to Practice of Impact Assessment for Infrastructure. In Impact Assessment and Human Well-Being, the $29^{\text {th }}$ Annual Meeting of the International Association for Impact Assessment, 17-22.

Fuchs, S., Birkmann, J., \& Glade, T. (2012). Vulnerability assessment in natural hazard and risk analysis: current approaches and future challenges. Natural Hazards, 1-7.

Fünfgeld, H. (2010). Institutional challenges to climate risk management in cities. Current Opinion in Environmental Sustainability, 2(3), 156-160.

Hansson, S. O. (2010). Risk: objective or subjective, facts or values. Journal of Risk Research, 13(2), 231-238.

Heinrich, C. J., \& Marschke, G. (2010). Incentives and their dynamics in public sector performance management systems. Journal of Policy Analysis and Management, 29(1), 183-208.

Helmstein M., Joachimsthaler, Erich A., \& Leppänen R. (1993). A Note on the Organizational Implications of Globalization. IESE, MN-281-E. Retrieved from http://protectedpdf.iese.edu/descargas/MN-281-E-1005311.pdf

Highway Asset Management Quick Start Guidance Note - Risk Assessment. (2009). UK Roads Board. Retrieved from http://www.ukroadsliaisongroup.org/en/utilities/documentsummary.cfm?docid=371E63ED-62FF-4CD4-B37E57DB4787DCF1

Hill, S. (n.d.). A Primer on Risk Management in the Public Service. University of Calgary, 1-17.

Hood, J., \& Kelly, S. (1999). The emergence of public sector risk management: The case of local authorities in Scotland. Policy Studies, 20(4), 273-283.

Huber, C., \& Imfeld, D. (2012). Operational Risk Management in Practice: Implementation, Success Factors and Pitfalls: Efficient Implementation for Midsize and Small Asset Managers, Hedge Funds, Private Equity Funds, Family Offices. Success Factors and Pitfalls: Efficient Implementation for Midsize and Small Asset Managers, Hedge Funds, Private Equity Funds, Family Offices.

Huckman, R. S. (2009). Are you having trouble keeping your operations focused? Harvard Business Review, 87(9), 90-95.

Insurance Bureau of Canada. (2011). Municipal Storm and Sanitary Infrastructure Risk Assessment Tool Project. Retrieved from http://www.ibc.ca/en/Natural_Disasters/documents/MRAT\%20Leavebehind_EN_Jun3-11.pdf

ISO/IEC. (2009). ISO/IEC 31010:2009 Information technology -- Risk management-Principles and Guidelines. Geneva, Switzerland: ISO/IEC.

ISO/IEC. (2009). ISO/IEC 31010:2009 Information technology -- Risk management - Risk Assessment techniques. Geneva, Switzerland: ISO/IEC.

ISO/IEC. (2009). ISO/IEC 31010:2009 Information technology -- Risk management - Vocabulary. Geneva, Switzerland: ISO/IEC.

Johnson, G., Scholes, K., \& Whittington, R. (2006). Exploring Corporate Strategy. London: FT-Prentice Hall. 
Khatri, K., \& Vairavamoorthy, K. (2011). A New Approach of Risk Analysis for Complex Infrastructure Systems under Future Uncertainties: A Case of Urban Water Systems. In Reston, VA: ASCE copyright Proceedings of the First International Symposium on Uncertainty Modeling and Analysis and Management (ICVRAM 2011), and the Fifth International Symposium on Uncertainty Modeling and Analysis (ISUMA); Hyattsville, Maryland, d 20110000. American Society of Civil Engineers.

Levine, R. (2006). Risk management systems: understanding the need.

Life Cycle Asset Management. (n.d). Retrieved from http://www.lce.com/pdfs/LCAM Whitepaper204.pdf

Lynch, D., \& Bendeli M. Risk-based approach to asset management. (n.d.). Sinclair Knight Merz Magazine. Retrieved from: http://www.tolerro.com/resources/achieve-issue-1-2012-edition-ofsinclair-knight-merz-magazine-risk-based-approach-to-asset-management/

Moble Measham, T. G., Preston, B. L., Smith, T. F., Brooke, C., Gorddard, R., Withycombe, G., \& Morrison, C. (2011). Adapting to climate change through local municipal planning: barriers and challenges. Mitigation and Adaptation Strategies for Global Change, 16(8), 889-909.

Mobley, R. K. (2011). What is Risk Management? Retrieved from http://www.lce.com/What_is_Risk_Management_430-item.html

Möderl, M., \& Rauch, W. (2011). Spatial risk assessment for critical network infrastructure using sensitivity analysis. Frontiers of Earth Science, 5(4), 414-420.

Municipal infrastructure is 'at risk' across Canada, report says. (2012, September 11). The Gazette. Retrieved from www.montrealgazette.com

New national report card says Canada's municipal infrastructure "at risk". (2012). Federation of Canadian Municipalities. Retrieved from www.fcm.ca

Nordgård, D. E., \& Solum, G. (2009, June). Experiences using quantitative risk assessment in distribution system asset management. In CIRED-20th International conference on electricity distribution, Prague.

Pearce, T., Ford, J. D., Caron, A., \& Kudlak, B. P. (2012). Climate change adaptation planning in remote, resource-dependent communities: An Arctic example. Regional Environmental Change, 12(4), 825-837.

Peck, A., Bowering, E., \& Simonovic, S. P. (2010). Assessment of climate change risk to municipal infrastructure: A City of London case study. In 11th Int. Environmental Specialty Conf., 2010 CSCE Annual General Meeting and Congress-Engineering a Sustainable World. Montreal: CSCE.

Peck, A., Bowering, L. \& Simonovic, S.P. (2010). Assessment of Climate Change Risk to Municipal Infrastructure - City of London. Retrieved from http://www.iclr.org/images/Simonovic_Friday_Forum_Oct_2010.pdf

Piatyszek, E., \& Karagiannis, G. M. (2012). A model-based approach for a systematic risk analysis of local flood emergency operation plans: a first step toward a decision support system. Natural hazards, 61(3), 1443-1462.

Piskorski, M. J. (2007). Choosing Corporate and Global Scope. Cases: Harvard Business School Publishing, 9-707.

Piyatrapoomi, N., Kumar, A., Robertson, N., \& Weligamage, J. (2004). Risk assessment in life-cycle costing for road asset management.

Plunkett, T., Municipal Government (2017). In the Canadian Encyclopedia. Retrieved from https:/www.thecanadianencyclopedia.ca/en/article/municipal-government

Poland, M. (n.d.). PAS 55 - What is it and what's the next step? Retrieved from $\mathrm{http}: / / \mathrm{www} .1 \mathrm{ce} . \mathrm{com} / \mathrm{PAS}$ 55_What is_it and whats the next_step_366-item.html

Poland, M. (n.d.). The Key to Risk Identification: How You Manage Asset Information. Retrieved from http://www.lce.com/The_Key_to_Risk_Identification_How_You_Manage_Asset_Information_4 31-item.html 
Poland, M. (n.d.). The Value of Risk-Based Asset Management. Retrieved from http://www.lce.com/The_Value_of_RiskBased_Asset_Management_381-item.html

Rahman, S. (2013). Infrastructure Asset Management: A Strategic Approach Toward Sustainability. Course conducted at EPIC (Educational Programs and Innovation Center).

Redding, M. (2007). Managing risk in facilities management outsourcing.

Redlein, A., Humhal, C., Getzner, M., Gutheil-Knopp-Kirchwald, G. (2013). Municipal Facility Management - a "life cycle orientation" approach of planned actions. In XXXVIII Congresso nazionale Istituto Nazionale di Urbanistica, 2013, Salerno, Palazzo del Comune, Italy.

Risk management: principles and guidelines. (2009). Sydney Wellington, N.Z: Standards Australia International Standards New Zealand.

Shahata, K., \& Zayed, T. (2010). Integrated decision-support framework for municipal infrastructure asset. In Proceedings of the Pipelines 2010 Conference. Keystone, CO., 10(41187), 420

Shortreed, J. (2010). Enterprise risk management and ISO 31000. Journal of policy engagement, 2(3), 810.

Slywotzky, A. J., \& Drzik, J. (2005). Countering the biggest risk of all. Harvard Business Review, 83(4), 78-88.

Svendsen, N. K., \& Wolthusen, S. D. (2012). Modelling approaches. In Critical Infrastructure Protection, 68-97. Springer Berlin Heidelberg.

ten Veldhuis, J. A. E., Harder, R. C., \& Loog, M. (2013). Automatic classification of municipal call data to support quantitative risk analysis of urban drainage systems. Structure and Infrastructure Engineering, 9(2), 141-150.

The City of Calgary. (n.d.). Calgary's Assets Management Strategy. Retrieved from http://www.calgary.ca/CS/IIS/Documents/PDF/asset-management-strategy.pdf?noredirect=1

The Five Biggest Risks to Effective Asset Management. (2012). Retrieved from http://www.lce.com/The_Five_Biggest_Risks_to_Effective_Asset_Management_367-item.html

Treasury, N. S. W. (2004). Total Asset Management. $\bar{T} A \bar{M} 2004$.

Tsimberg, Y. (2009). Use of Asset Management Risk Assessment Methodology for Public Safety Analysis [Powerpoint Slides]. Retrieved from: http:/www.esasafe.com/assets/files/esaeds/pdf/ALL/Useof-Asset-Management-Risk-Assessment-Methodology-for-Public-Safety-Analysis.pdf

Turner, K. \& Clarke, N. (2004). Facility management guidelines to managing risk. Carlton, Vic: FMA Australia.

Vanier, D. J., \& Danylo, N. H. (1998). Municipal infrastructure investment planning: asset management. In Innovations in Urban Infrastructure Seminar of the APWA International Public Works Congress, 25-39. 